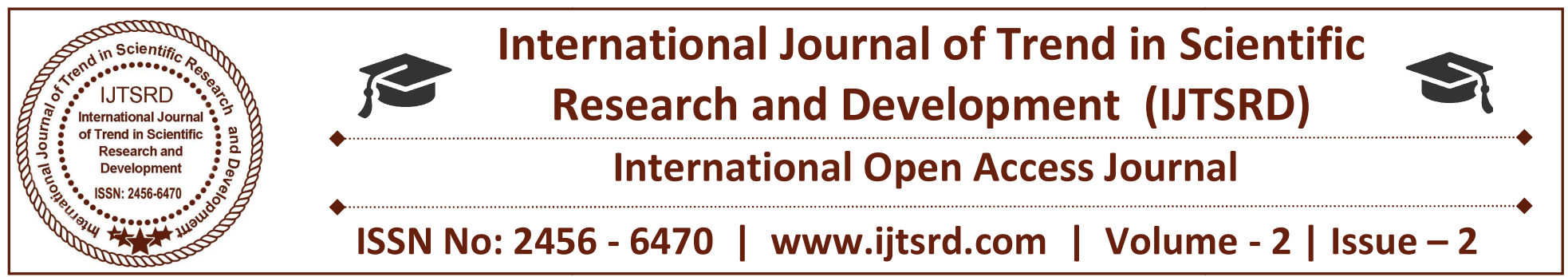

\title{
Review Paper for Design and Simulation of a Patch antenna by using HFSS
}

\section{Prof. Kazi K.S}

Department of Electronics \& Telecommunication Engineering, Brahmdevdada Mane Institute of Technology, Solapur, Maharashtra, India
Miss. Argonda U.A

Department of Electronics \& Telecommunication Engineering, Brahmdevdada Mane Institute of Technology, Solapur, Maharashtra, India

\section{ABSTRACT}

In modern times needs for Broadband application has increased. In resent year many work done by design of antenna system. T-shape slot antenna has nearly omnidirectional radiation patter for all operating bands and gain variation of the range in each of the bands can be less than $3 \mathrm{dBi}$. The maximum impedance bandwidth reaching about $121 \%$ has been obtained and the size of the proposed antenna is reduced by $26.5 \%$. In this paper we compare the parameters of T-shape slot antenna, Micro strip patch antenna, Horn antenna, slot antenna for wideband application.

\section{Keyword: Radiation patter, impedance,} communication system, Omni directional, Micro strip patch antenna

\section{INTRODUCTION}

Antenna is the main source for any communication system. All Antennas such T-shape slot antenna, Micro strip patch Antenna, Folded Slot antenna, slot antenna are passive devices. In that antennas radiated

Power cannot be greeter then transmission power.[2]

\section{T-SHAPE SLOT ANTENNA}

Among various forms of planar antennas, coplanar waveguide-fed printed slot antennas have the simplest structure of a single metallic layer. Because the slot antennas have the advantages of wide bandwidth and easy integration with monolithic microwave integrated circuit, the designs of the T-shape slot antennas have recently received much attention.
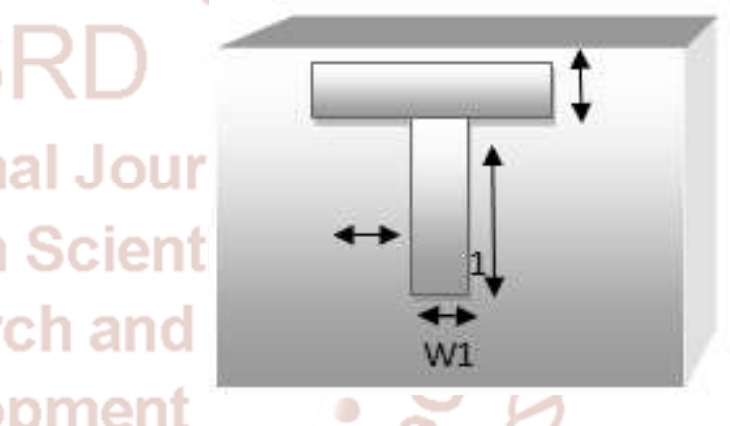

Fig (1) T-shape slot antenna

The antenna shape and its dimensions were first searched by using the Ansoft's High Frequency Structure Simulator (HFSS) and then the optimal dimensions were determined from experimental adjustment.

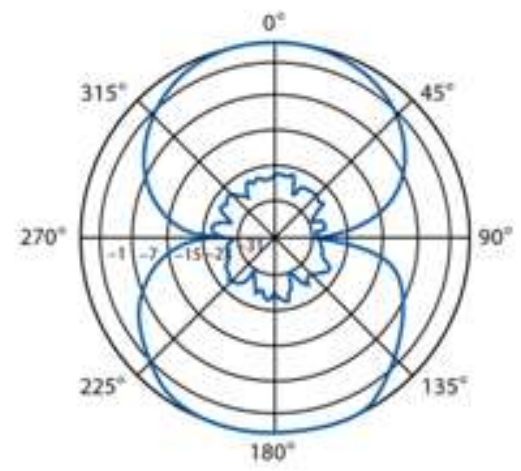

Fig (2) Radiation pattern 


\section{MICRO STRIP PATCH ANTENNA}

The simplest patch antenna uses a patch which is onehalf wave length long, mounted a precise distance above a larger ground plane, sometimes using a spacer made of a dielectric between them. Electrically large ground planes produce stable patterns and lower environmental sensitivity but of course make the antenna bigger. It isn't uncommon for the ground plane to be only modestly larger than the active patch.

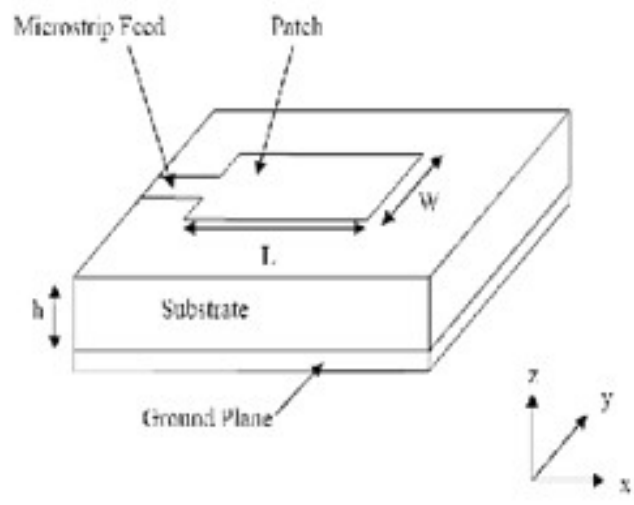

Fig (3)Micro strip patch antenna find its radiation characteristics the equivalent principle techniques can be utilized.

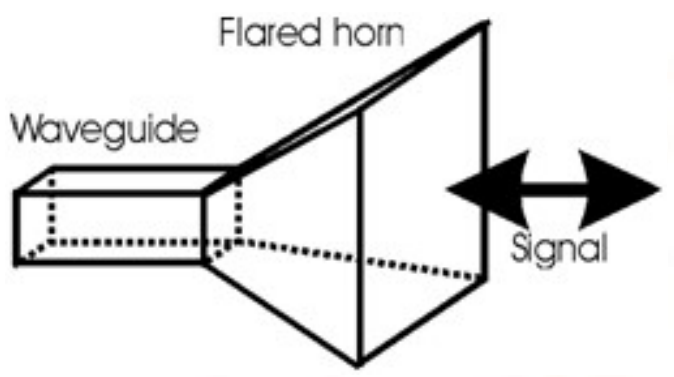

Fig (5) Horn antenna

To develop an exact equivalent of it, it is necessary that the tangential electric and magnetic field components over a closed surface are known. The closed surface that is usually selected is an infinite plane that coincides with the aperture of the horn.

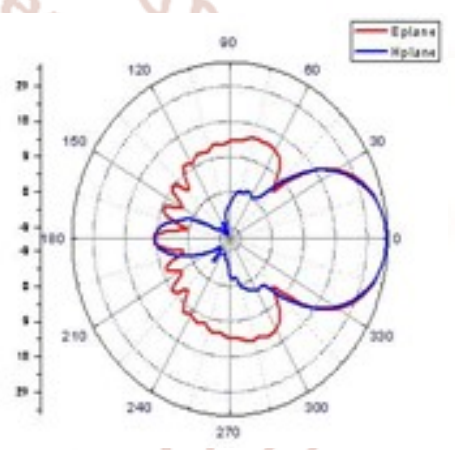

Fig (6) Radiation pattern

5. EXPERIMENT RESULTS

Simulated and measured input return losses are shown and compared in Figure 7.

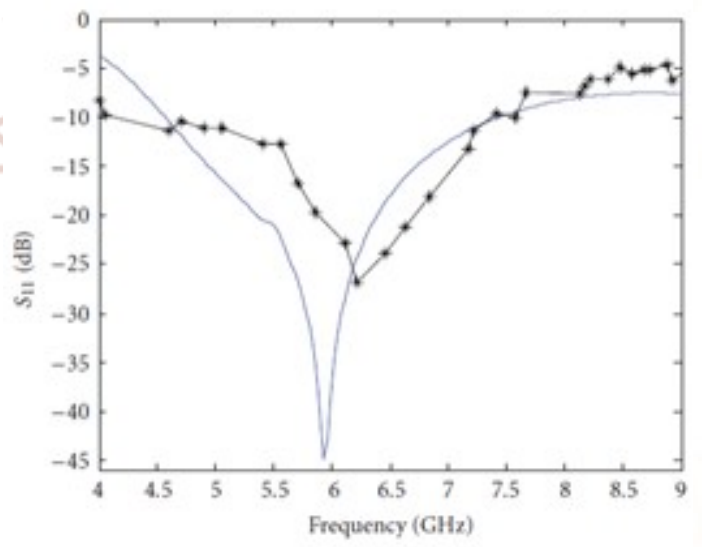

Fig (7) Return loss versus frequency attractive features like light weight, low VSWR, low profile and compatibility. As it is being flared in both directions its radiations characteristics are essentially a combination of the e- and h-plane sect oral horns and its geometry Coordinate system is shown in Fig.5. The horn can be treated as an aperture antenna. To
The figure shows the radiation pattern of Micro strip patch antenna which is Omni direction.

\section{HORN ANTENNA}

The pyramidal horns are popular for their well known 
and measured results are in good agreement, it can be made still better if fabrication precision is increased.

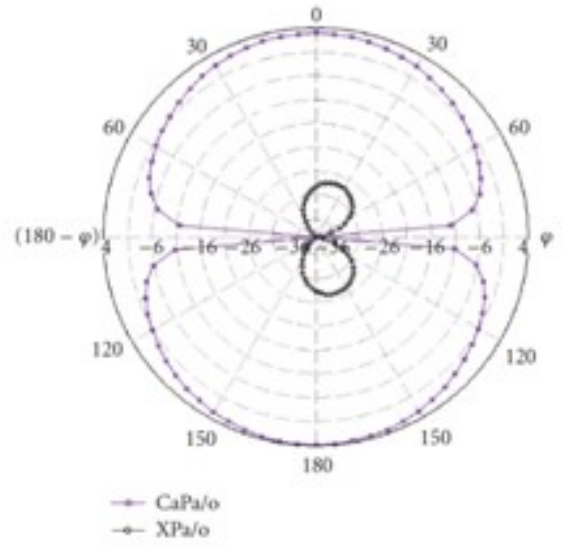

(a) E-plane pattern $(\mathrm{dBi})$

Fig (8) Radiation patterns of antenna measured at 6.06 GHz.

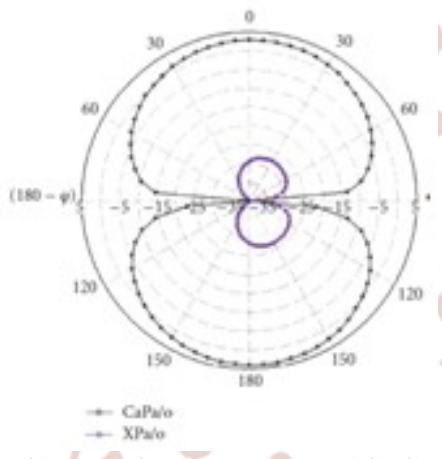

8. (b) H-plane pattern (dBi).

Due to limited testing facilities, only simulated radiation patterns are presented. The E- and H-plane radiation patterns simulated at $6.06 \mathrm{GHz}$ are shown in Figures 8 (a) and $8(\mathrm{~b})$, respectively. The radiation patterns are bidirectional in the E-plane and H-plane. It should be noted that cross polarization levels are well controlled in E-plane and H-plane. Moreover, antenna is linearly polarized.

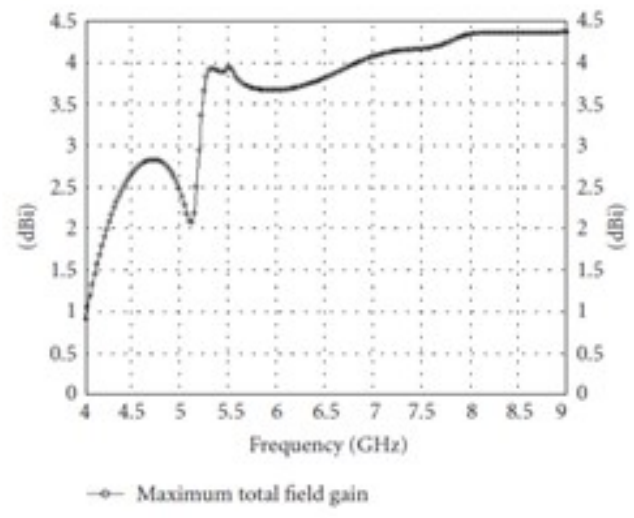

Fig (9) Gain versus frequency.
The gain-versus-frequency characteristics are given in Figure 9. The simulated peak antenna gain is $4.39 \mathrm{dBi}$ at 8 $\mathrm{GHz}$.

\section{CONCLUSION}

The Broadband T-Shape slot antenna has the advantage over all the antenna is that, it has the less return loss, i.e. 10-dB. Omnidirectional radiation pattern, It is because the symmetrical configuration of the T-shape slot antenna, and it has a peak antenna gain of about $4.8 \mathrm{dBi}$, with gain variations less than 3 $\mathrm{dBi}$ across the operating bandwidth from $1.8 \mathrm{GHz}$ to $6 \mathrm{GHz}$. In addition to the advantages of low cost, simple structure, and wide operating band, the Tshape slot antenna has nearly omnidirectional radiation for all operating bands including PCS, 3G, Bluetooth, DMB and WANL and gain variation of the range in each of the bands can be less than $3 \mathrm{dBi}$.

\section{REFERENCES}

1. Chen, J.S. 'Triple-frequency annular-ring slot antennas fed by CPWandmicrostrip line'. IEEE APS Int. Symp., 2003, Vol. 2, pp. 557-560.

2. Abhilasha Mishra et. al., "The design of circular Microstrip patch antenna by using Quasi-Newton Algorithm of ANN", Journal of Electromagnetic Analysis \& Applications, pp. 444 to449, 2010.

3. D. D. Krishna et. al., "Compact Dual Band Slot Loaded Circular Microstrip Antenna with a Superstrate"Progress In Electromagnetics Research, PIER 83, 245-255, 2008.

4. N. Kulkarni et. al., "Design And Development of Corner Truncated U nd Inverted U-Slot Multiband Tunable Rectangular Microstrip Antenna", Progress In Electromagnetics Research Letters, Vol. 29, 185199, 2012.

5. J.-J. Jiao, G. Zhao, F.-S. Zhang, H.-W. Yuan, and Y.C. Jiao, "Broadband CPW-fed T-shape slot antenna, Progress In Electromagnetics Research, PIER 76, 2007.

6. Sonali Jain, Prof. Rajesh Nema, "Review paper circularMicrostrip patch Antenna,'International Journal of Computer Technology and electronics Engineering (IJCTEE) Volume1,Issue 3.

7. S.-Y. Chen and P. Hsu, "CPW-fed Foldedslotantenna for $5.8 \mathrm{GHz}$ RFIDTags,"Electronics Letters $25^{\text {th }}$ November 2004 Vol. 40 No. 24. 